\title{
Reducing cholinergic constriction: the major reversible mechanism in COPD
}

\author{
V. Brusasco
}

ABSTRACT: The airway narrowing in chronic obstructive pulmonary disease (COPD) has often been misunderstood as being irreversible. However, a large proportion of patients with COPD do respond to bronchodilator agents with significant changes in lung function.

Unlike in asthma, abnormalities in airway smooth muscle structure or function are not believed to play a key role in COPD airway narrowing. Although there are only limited data suggesting that cholinergic tone may be increased in COPD, the well-documented efficacy of antimuscarinic agents in increasing airway calibre suggests that cholinergic tone represents the major reversible component of airflow obstruction in these patients. Airway wall thickening and loss of airway-toparenchyma interdependence are nonreversible components of airflow obstruction in COPD that may amplify the effect of changes in airway smooth muscle tone. Thus, keeping airway smooth muscle tone to a minimum might offer patients long-lasting airway patency and protection against breathlessness, which is the major complaint of patients with COPD.

Receptor antagonism by anticholinergic agents can achieve effective relaxation of airway smooth muscle in COPD. According to a classical view of cholinergic receptor function and distribution, the ideal anticholinergic bronchodilator would be one that blocks both $M_{1}$ and $M_{3}$ receptors, which mediate airway smooth muscle contraction, but not the $M_{2}$ receptor, stimulation of which reduces acetylcholine release from vagus nerve endings and prevents the airway smooth muscle from contracting by excessive increments.

Agents with such pharmacodynamic selectivity are not available, but effective and prolonged inhibition of airway smooth muscle tone has been obtained with tiotropium, which binds to all three major muscarinic receptor subtypes, but for much longer to $M_{3}$ than to $M_{2}$ receptors. Recent data show that long-term treatment with tiotropium for 1 yr helps sustain 24-h airway patency. This sustained effect may help to explain the improvements in both exacerbation rate and lung function observed in chronic obstructive pulmonary disease patients treated with tiotropium.

KEYWORDS: Anticholinergic agents, bronchodilators, chronic obstructive pulmonary disease

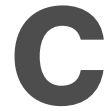
hronic obstructive pulmonary disease (COPD) and asthma are both obstructive airway diseases; however, they have distinct pathological and clinical differences. The underlying chronic airway inflammation in asthma is mainly eosinophilic and driven by CD4+ T-cells, while in COPD it is neutrophilic and characterised by the presence of increased numbers of macrophages and CD8+ T-cells [1]. In addition, airflow obstruction in asthma is often completely reversible, either spontaneously or with treatment, while in COPD it is never fully reversible and is usually progressive, particularly if exposure to noxious agents continues. This is reflected in the recent American Thoracic Society and European Respiratory Society joint statement, which defined COPD as a "preventable and treatable disease state characterised by airflow limitation that is not fully reversible" [2].
Although, by definition, the airflow obstruction of COPD is not fully reversible, many individuals do show significant, albeit partial, reversibility following bronchodilator administration. For instance, a retrospective analysis of two 6-month trials showed that more than half of patients with moderate-to-severe COPD do respond to bronchodilator treatment with increments of forced expiratory volume in one second (FEV1) or forced vital capacity of $\geqslant 200 \mathrm{~mL}$ and $15 \%$ from baseline [3].

It is now generally accepted that airflow obstruction in COPD, although not fully reversible, is in fact determined by both irreversible and reversible components. The aim of the present article is to describe these components of airflow obstruction in COPD, with a view to explaining how bronchodilators can effectively increase airway calibre.
CORRESPONDENCE

V. Brusasco

Departimento di Medicina Interna

Università di Genova

Viale Benedetto XV 6 16132 Genova

Italy

Fax: 39103537690

E-mail: vito.brusasco@unige.it

CONFLICT OF INTEREST STATEMENT V. Brusasco has been a consultant for Boehringer Ingelheim (Milan, Italy), Pfizer (Rome, Italy), Chiesi Farmaceutici (Parma, Italy), Lofarma (Milan), and Merck Sharp and Dohme (Rome). He also participates in an Altana Advisory Board (Milan) and has received honoraria from Boehringer Ingelheim, Pfizer and Novartis (Origgio, Italy) for his participation at symposia. He has received a research grant from Altana and has been involved in multicentre clinical trials for Boehringer Ingelheim, Chiesi and GlaxoSmithKline (Verona, Italy). 


\section{AIRFLOW OBSTRUCTION IN COPD}

The calibre of the intrapulmonary airways is dependent upon the force generated by the smooth muscle, the load it works against and the geometry of the airway wall [4]. In healthy lungs, airway smooth muscle maintains a low-level basal bronchomotor tone due to stimulation by acetylcholine released from the vagus nerve [5]. The influence of this basal tone on airway resistance is normally minimal, but the effect is nevertheless detectable as a small bronchodilator response to anticholinergic drugs [6]. The low baseline level of cholinergic tone of airway smooth muscle may have a far greater proportional effect on airway resistance in the intrinsically narrowed airways than in normal airways for geometric reasons [5], because the resistance to airflow of an airway is inversely proportional to the fourth power of its internal radius.

In asthma, the airway smooth muscle is thicker than normal, and an increased ability to generate force is considered to be the major mechanism for airway narrowing [7]. In COPD, the airway smooth muscle has a near-normal thickness, and the ability to generate force is weakly correlated with the degree of airflow obstruction [8]. It is therefore believed that airway narrowing in COPD is mainly due to the increased thickness of the airway wall and the loss of elastic load (due to disruption of alveolar attachments; fig. 1) [9]. These nonreversible (structural) changes amplify the effects of changes in airway smooth muscle tone.

The intracellular mechanisms involved in regulating airway smooth muscle tone have been well studied [10]. Circulating catecholamines activate surface $\beta_{2}$-adrenoceptors, which are coupled to adenylate cyclase via a Gs protein. This causes an increase in intracellular cyclic adenosine monophosphate (cAMP), which activates protein kinase A (PKA). PKA, in turn, phosphorylates several proteins inside the cell, leading to relaxation of the airway smooth muscle. Muscarinic receptors $\left(\mathrm{M}_{3}\right.$ receptors) are coupled via $\mathrm{Gq}$ proteins to phospholipase $\mathrm{C}$ (PLC), which promotes the formation of inositol 1,4,5trisphosphate and the release of intracellular calcium, thus leading to contraction of airway smooth muscle. The $\mathrm{M}_{3}$ receptors of the smooth muscle cell membrane are activated by the acetylcholine released from post-ganglionic cholinergic fibres of the parasympathetic nervous system, causing bronchoconstriction [5]. In addition, cholinergic pathways may be activated by inflammatory mediators or cigarette smoke through the reflex action of C-fibre nerves that stimulate the parasympathetic ganglia. The C-fibres originate from the irritant receptors within the airway wall. In this way, there is a direct link between airway irritants and acute airway smooth muscle constriction, although the role in more chronic changes in airway muscle tone is unclear.

In asthma, adrenergic agonists are generally more potent bronchodilators than anticholinergic agents. However, there is some evidence that patients with COPD respond similarly to both types of agents. Ipratropium (an anticholinergic agent) caused a similar rapid bronchodilation in patients with either asthma or bronchitis, whereas fenoterol (an adrenergic agent) plus theophylline induced a considerably greater effect in the former condition [11]. One explanation as to why patients with COPD respond similarly to anticholinergic and adrenegeric

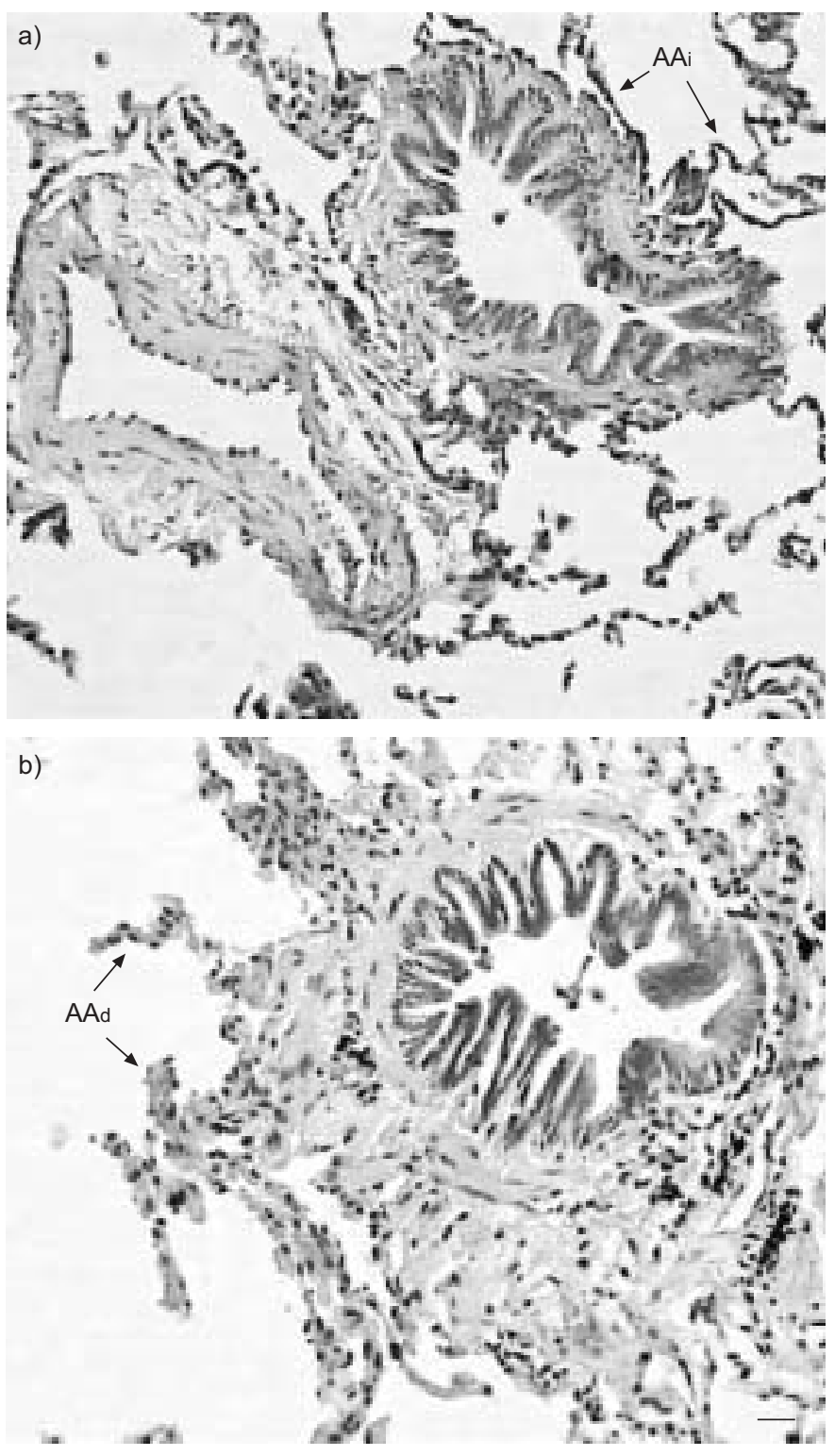

FIGURE 1. Microphotographs showing peripheral airways of similar size from patients a) without and b) with airway obstruction, defined as forced expiratory volume in one second/forced vital capacity $<0.7$. Note the thicker airway wall in the obstructed subject. AAi: intact alveolar attachments; AAd: destroyed alveolar attachments. Scale bars $=20 \mu \mathrm{m}$. Reprinted from [9] with permission from the publisher.

agents is that the major reversible component of their airway narrowing is due to cholinergic bronchomotor tone, which can be equally reduced by blocking cholinergic neurotransmission or by directly relaxing the airway smooth muscle.

The relative contributions of cholinergic (parasympathetic) and noncholinergic mechanisms in airflow obstruction in patients with emphysema were studied by administering supramaximal doses of an anticholinergic agent (atropine methonitrate) and an adrenergic agent (salbutamol) in sequence and in combination [12]. Serial doses of one agent were administered to achieve a plateau of bronchodilation, then the other agent was administered. The anticholinergic agent alone produced as much bronchodilation as could be achieved with maximal 
doses of either agent alone or in combination, supporting the concept that cholinergic activity is the dominant reversible component of airflow limitation in this disease.

The question arises: is cholinergic tone increased in patients with COPD compared with healthy subjects? Cholinergic tone can be indirectly estimated in vivo by measuring the increase in FEV1 following the administration of an anticholinergic agent. Using this method, Gross et al. [6] lent support to the notion that cholinergic tone is increased in patients with COPD compared with healthy subjects, with the increase in FEV1 being directly proportional to disease severity [6]. Furthermore, two-thirds of the day-to-day variation in baseline airflow in patients with COPD can be attributed to variations in cholinergic tone [6]. However, the relative roles of smooth muscle contraction and structural changes in airway calibre cannot be separated in vivo; this topic therefore remains unresolved.

\section{REDUCING CHOLINERGIC TONE IN COPD}

Acetylcholine stimulates cholinergic receptors, which can be divided into nicotinic and muscarinic receptors. Three muscarinic receptor subtypes have been found in human airways: $\mathrm{M}_{1}, \mathrm{M}_{2}$ and $\mathrm{M}_{3}$ [13]. A classic scheme of the location of each receptor subtype and its function in airway tone is shown in figure 2. $\mathrm{M}_{1}$ and $\mathrm{M}_{3}$ receptors, upon stimulation with acetylcholine, mediate the cholinergic effect, causing airway narrowing. $\mathrm{M}_{2}$ receptors, when engaged by acetylcholine, deliver a negative feedback signal to the pre-junctional nerve ending, diminishing further release of acetylcholine [14]. According to this view, the ideal anticholinergic agent would be one that preferentially blocks $\mathrm{M}_{1}$ and $\mathrm{M}_{3}$ receptors, and maintains the function of the $\mathrm{M}_{2}$ receptor. However, there are reasons why a fully $\mathrm{M}_{3}$-selective agent may not be necessary to obtain an optimal bronchodilator effect. First, if blockade of all $\mathrm{M}_{3}$ receptors was achieved, any increase in acetylcholine release would not have an additional effect on muscle contraction. Secondly, $\mathrm{M}_{2}$ receptors are also present in the smooth muscle cell membrane and their activation inhibits adenylate cyclase, thus reducing the relaxant response to

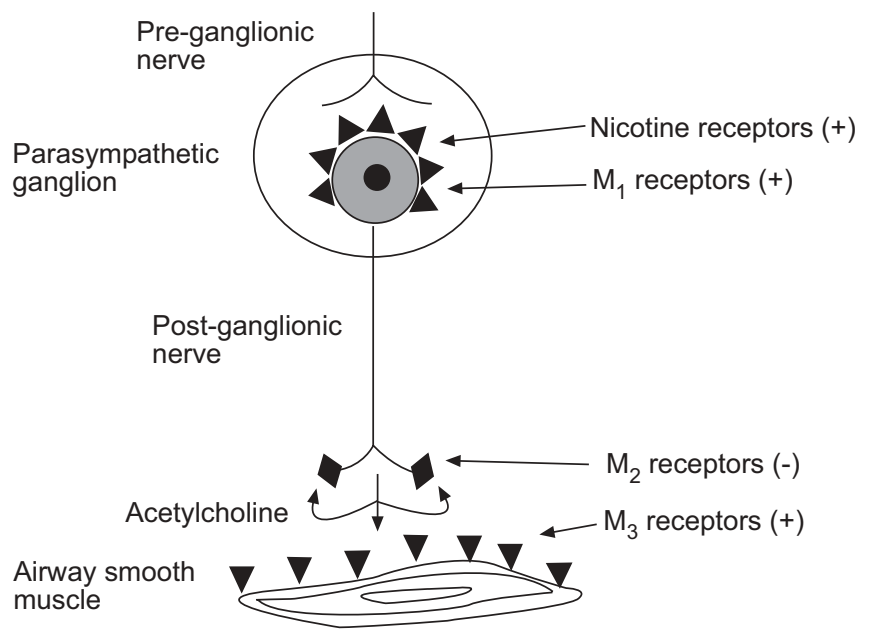

FIGURE 2. Cholinergic regulation of airway smooth muscle tone. (+): increased cholinergic tone when stimulated; (-): decreased cholinergic tone when stimulated. Reprinted from [13] with permission from the publisher. $\beta$-receptor stimulation [15]. Therefore, blockade of the postjunctional $\mathrm{M}_{2}$ receptor would favour accumulation of intracellular cAMP and smooth muscle relaxation.

Tiotropium is a once-daily, inhaled anticholinergic agent that acts through prolonged $\mathrm{M}_{3}$ receptor blockade. Table 1 compares tiotropium and ipratropium in terms of their binding affinity to cloned human $\mathrm{M}_{1}$ and $\mathrm{M}_{3}$ receptors expressed in Chinese hamster ovary cells and the dissociation half-life of the receptor-drug complex [16]. In the in vitro study [16], dissociation half-lives for tiotropium-muscarinic receptor complexes were two orders of magnitude longer than those of ipratropium-muscarinic receptor complexes. Although tiotropium is not subtype-selective in the classic pharmacodynamic view, because the binding affinity is similar for all three subtypes, the much longer binding to $M_{3}$ than to $M_{2}$ receptors provides a type of pharmacokinetic selectivity.

Data show that tiotropium $(18 \mu \mathrm{g})$ administered once daily to patients with COPD increases FEV1, with sustained 24-h action (fig. 3) [17]. Patients were administered once-daily tiotropium at either 09:00 $\mathrm{h}$ or 21:00 $\mathrm{h}$ (with placebo administered at the alternative time), or twice-daily placebo in a repeated-dose, parallel-group study, specifically designed to determine whether the time of dosing at steady state influences the bronchodilator response. Tiotropium significantly increased FEV1 above placebo over the 24-h period, regardless of whether it was given in the morning or the evening. During the night, FEV1 showed a decline between 03:00 $\mathrm{h}$ and 06:00 $\mathrm{h}$ [17]. Tiotropium effectively limited the early morning decline in FEV1 observed in patients with COPD who received placebo [17].

Although it is rational to begin bronchodilator therapy with a single agent, most patients with COPD will have only modest responses to single agents. The addition of a second or third bronchodilator with different mechanisms of action can result in improved bronchodilator and clinical effect. A recent 6-week study in moderate-to-severe COPD patients showed that a combination treatment with tiotropium and formoterol provides significant additive improvements in daytime and nighttime lung function compared with single-agent therapy [18]. Positive interactions between antimuscarinic and $\beta$-agonist agents may stem from different mechanisms. First, stimulation of pre-junctional $\beta$-adrenoceptors may reduce acetylcholine release, although this effect differs between species [19-22]. Secondly, blockade of post-junctional $\mathrm{M}_{2}$ receptors may enhance the relaxant response to $\beta$-agonists, by increasing

\begin{tabular}{|c|c|c|c|c|}
\hline TABLE 1 & $\begin{array}{l}\text { Binding } \\
\text { of tiotro }\end{array}$ & $\begin{array}{l}\text { es anc } \\
\text { nd ipr }\end{array}$ & $\begin{array}{l}\text { ciation } \\
\text { im }\end{array}$ & es $(t 1 / 2)$ \\
\hline \multirow[t]{2}{*}{ Receptor } & \multicolumn{2}{|c|}{ Tiotropium } & \multicolumn{2}{|c|}{ Ipratropium } \\
\hline & KD nM & $t 1 / 2 h$ & KD nM & $t_{1 / 2 h}$ \\
\hline$M_{1}$ & 0.041 & 14.6 & 0.183 & 0.110 \\
\hline$M_{2}$ & 0.021 & 3.6 & 0.195 & 0.035 \\
\hline$M_{3}$ & 0.014 & 34.7 & 0.204 & 0.260 \\
\hline
\end{tabular}

KD: kinetically determined dissociation constant. Reprinted from [16] with permission from the publisher. 


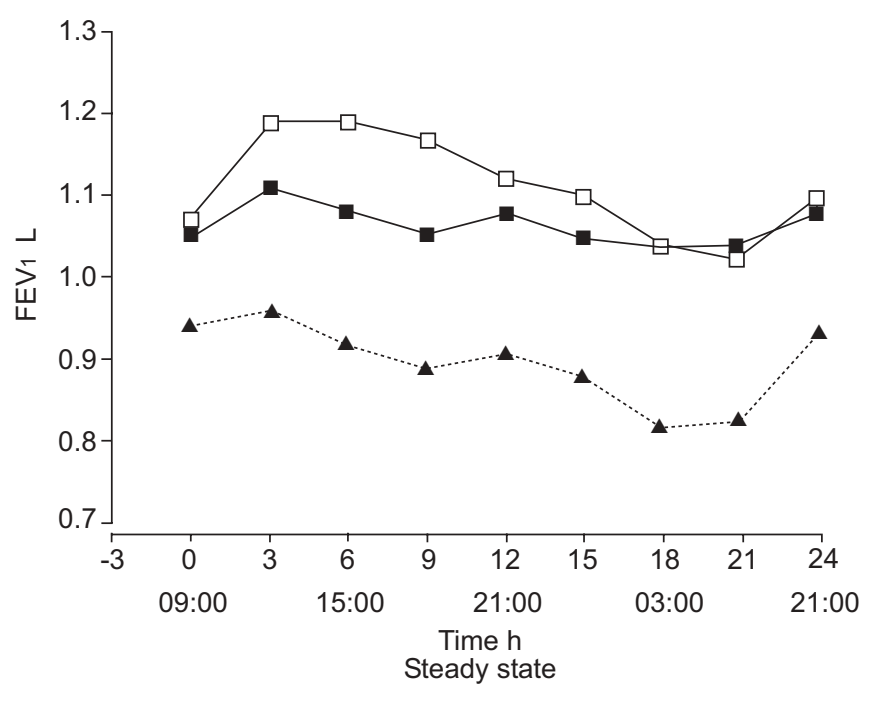

FIGURE 3. Improvement in forced expiratory volume in one second over $24 \mathrm{~h}$ by cholinergic blockade. tiotropium pm ( $n=35) ; \square$ : tiotropium am ( $n=37) ; \boldsymbol{\Delta}$ placebo $(n=33)$. Reprinted from [17] with permission from the publisher.

cAMP production. Thirdly, blockade of $\mathrm{M}_{2}$ and $\mathrm{M}_{3}$ receptors may counterbalance the possible upregulation of PLC induced by long-term $\beta$-receptor stimulation [23].

Maintaining 24-h airway patency may help to reduce the rate of COPD exacerbations. Several large-scale studies have shown that tiotropium significantly reduces the number of exacerbations and delays the time to first exacerbation compared with placebo or ipratropium [24-27]. The mechanisms by which tiotropium might reduce the frequency of exacerbations remain to be defined. However, the sustained 24-h bronchodilation, and consequent reduction in lung hyperinflation afforded by maintenance tiotropium treatment, may allow patients to withstand an insult for longer before experiencing intolerable breathlessness, which is a key symptom during an exacerbation. Because exacerbations are related to FEV1 decline [28], it can be postulated that this effect may also lead to a reduced decline in lung function. A re-analysis of the data from the 1-yr tiotropium trials suggests that tiotropium may affect the long-term decline in lung function in patients with COPD [29]. The decline in trough FEV1 was, on average, $12 \mathrm{~mL}$ in the tiotropium-treated patients and $58 \mathrm{~mL}$ in the placebotreated patients. A similar trend was also present in the 3-h post-dose FEV1, although its magnitude was considerably less. Longer-term trials specifically designed to study this effect are required to confirm this observation.

A hypothetical mechanism by which bronchodilator treatment may reduce the frequency of exacerbations and the decline in lung function is outlined below. In patients with COPD, some airways close at lung volumes within the resting tidal volume range. The cyclical closure and re-opening of the small airways during tidal breathing may cause or worsen airway wall injury due to repeated mechanical stress. In the long term, this might result in an accelerated decline in lung function. As mentioned previously, repeated exacerbations also lead to airway wall injury and may contribute to the rapid decline in lung function.
Maintaining airway patency may prevent the decline in lung function by reducing mechanical stress on the airway walls. Although exacerbations may still occur, the healing of the lung is not hampered and, therefore, the decline in lung function is slower. Thus, effective 24-h bronchodilation may have not only a symptomatic effect but also a favourable impact on the progression of the disease.

\section{CONCLUSIONS}

The airflow obstruction in COPD has often been misunderstood as being irreversible. However, a number of patients with moderate-to-severe COPD show significant reversibility in their airflow obstruction in response to bronchodilator agents. It is now accepted that airflow obstruction in COPD, although not fully reversible, is in fact determined by both irreversible and reversible components. Although airway smooth muscle does not appear to be abnormal in COPD, the effects of its contraction/relaxation on airway resistance may be amplified due to nonreversible structural changes, such as airway wall thickening and loss of airway-to-parenchyma interdependence.

Airway smooth muscle tone is primarily sustained by cholinergic activity, which may be increased in chronic obstructive pulmonary disease. Therefore, inhibition of cholinergic activity by anticholinergic agents is a logical therapeutic means of increasing airflow in chronic obstructive pulmonary disease. Tiotropium maintains 24-h airway patency in patients with chronic obstructive pulmonary disease. Analyses of longterm treatment suggest that tiotropium reduces the occurrence of exacerbations and may also slow the decline in lung function. Because tiotropium acts by reducing airway smooth muscle tone, it can be speculated that these effects are related to sustained 24-h airway patency.

\section{REFERENCES}

1 Global Initiative for Chronic Obstructive Lung Disease. Global strategy for the diagnosis, management, and prevention of chronic obstructive pulmonary disease. www.goldcopd.com 2005. Date last accessed: September 25, 2006.

2 Celli BR, MacNee W, ATS/ERS Task Force. Standards for the diagnosis and treatment of patients with COPD: a summary of the ATS/ERS position paper. Eur Respir J 2004; 23: 932-946.

3 Brusasco V, Menjoge S, Kesten S. Flow and volume responders following treatment with tiotropium and salmeterol in patients with COPD. Am J Respir Crit Care Med 2003; 167: A320.

4 Moreno RH, Hogg JC, Pare PD. Mechanics of airway narrowing. Am Rev Respir Dis 1986; 133: 1171-1180.

5 Barnes PJ. Managing chronic obstructive pulmonary disease. London, Science Press, 1999; pp. 1-80.

6 Gross NJ, Co E, Skorodin MS. Cholinergic bronchomotor tone in COPD. Estimates of its amount in comparison with that in normal subjects. Chest 1989; 96: 984-987.

7 Lambert RK, Wiggs BR, Kuwano K, et al. Functional significance of increased airway smooth muscle in asthma and COPD. J Appl Physiol 1993; 74: 2771-2781. 
8 Opazo Saez AM, Seow CY, Pare PD. Peripheral airway smooth muscle mechanics in obstructive airways disease. Am J Respir Crit Care Med 2000; 161: 910-917.

9 Corsico A, Milanese M, Baraldo S, et al. Small airway morphology and lung function in the transition from normality to chronic airway obstruction. J Appl Physiol 2003; 95: 441-447.

10 Barnes PJ. Bronchodilators: basic pharmacology. London, Chapman and Hall, 1995; pp. 391-417.

11 Lefcoe NM, Toogood JH, Blennerhassett G, et al. The addition of an aerosol anticholinergic to an oral beta agonist plus theophylline in asthma and bronchitis. A double-blind single dose study. Chest 1982; 82: 300-305.

12 Gross NJ, Skorodin MS. Role of the parasympathetic system in airway obstruction due to emphysema. $N$ Engl J Med 1984; 311: 421-425.

13 Barnes PJ. New developments in anticholinergic drugs. Eur Respir Rev 1996; 6: 290-294.

14 Blaber LC, Fryer AD, Maclagan J. Neuronal muscarinic receptors attenuate vagally-induced contraction of feline bronchial smooth muscle. Br J Pharmacol 1985; 86: 723-728.

15 Jones CA, Madison JM, Tom-Moy M, et al. Muscarinic cholinergic inhibition of adenylate cyclase in airway smooth muscle. Am J Physiol 1987; 253: C97-C104.

16 Disse B, Speck GA, Rominger KL, et al. Tiotropium $\left(\right.$ Spiriva $\left.{ }^{\mathrm{TM}}\right)$ : mechanistical considerations and clinical profile in obstructive lung disease. Life Sci 1999; 64: 457-464.

17 Calverley PM, Lee A, Towse L, et al. Effect of tiotropium bromide on circadian variation in airflow limitation in chronic obstructive pulmonary disease. Thorax 2003; 58: 855-860.

18 van Noord JA, Aumann JL, Janssens E, et al. Comparison of tiotropium once daily, formoterol twice daily and both combined once daily in patients with COPD. Eur Respir J 2005; 26: 214-222.

19 Rhoden KJ, Meldrum LA, Barnes PJ. Inhibition of cholinergic neurotransmission in human airways by beta 2-adrenoceptors. J Appl Physiol 1988; 65: 700-705.

20 Zhang XY, Olszewski MA, Robinson NE. Beta 2-adrenoceptor activation augments acetylcholine release from tracheal parasympathetic nerves. Am J Physiol 1995; 268: L950-L956.

21 Wessler I, Reinheimer T, Brunn G, et al. Beta-adrenoceptors mediate inhibition of $\left[{ }^{3} \mathrm{H}\right]$-acetylcholine release from the isolated rat and guinea-pig trachea: role of the airway mucosa and prostaglandins. Br J Pharmacol 1994; 113: 1221-1230.

22 Brichetto L, Song P, Crimi E, et al. Modulation of cholinergic responsiveness through the $\beta$-adrenoceptor signal transmission pathway in bovine trachealis. J Appl Physiol 2003; 95: 735-741.

23 McGraw DW, Almoosa KF, Paul RJ, et al. Antithetic regulation by beta-adrenergic receptors of $\mathrm{Gq}$ receptor signaling via phospholipase $C$ underlies the airway betaagonist paradox. J Clin Invest 2003; 112: 619-626.

24 Vincken W, van Noord JA, Greefhorst APM, et al. Improved health outcomes in patients with COPD during $1 \mathrm{yr}$ 's treatment with tiotropium. Eur Respir $J$ 2002; 19: 209-216.

25 Brusasco V, Hodder R, Miravitlles M, et al. Health outcomes following treatment for six months with once daily tiotropium compared with twice daily salmeterol in patients with COPD. Thorax 2003; 58: 399-404.

26 Casaburi R, Mahler DA, Jones PW, et al. A long-term evaluation of once-daily inhaled tiotropium in chronic obstructive pulmonary disease. Eur Respir J 2002; 19: 217-224.

27 Niewoehner DE, Rice K, Cote C, et al. Prevention of exacerbations of chronic obstructive pulmonary disease with tiotropium, a once-daily inhaled anticholinergic bronchodilator: a randomized trial. Ann Intern Med 2005; 143: 317-326.

28 Donaldson GC, Seemungal TAR, Bhowmik A, et al. Relationship between exacerbation frequency and lung function decline in chronic obstructive pulmonary disease. Thorax 2002; 57: 847-852.

29 Anzueto A, Tashkin D, Menjoge S, et al. One-year analysis of longitudinal changes in spirometry in patients with COPD receiving tiotropium. Pulm Pharmacol Ther 2005; 18: 75-81. 